\title{
CORRELATIONS INVOLVING OIL AND FATTY \\ ACIDS IN RAPESEED
}

\author{
A thesis \\ submitted to \\ The Faculty of Graduate Studies and Research \\ The University of Manitoba
}

\author{
In Partial Fulfillment \\ of the Requirements for the Degree \\ Doctor of Philosophy
}

by

Baldur Rosmund Stefansson

May 1966

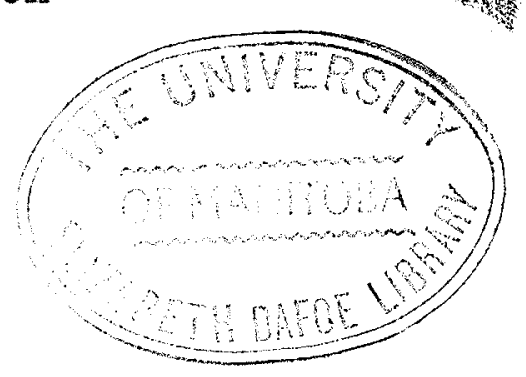


TABLE OF CONTENTS

PAGE

INTRODUCTION ....................... 1

LITERATURE REVIEW . . . . . . . . . . . . 3

MATERIALS AND METHODS . . . . . . . . . . . 9

RESULTS ................. 12

Preliminary Data . . . . . . . . . . 12

Characteristics of Four Populations of Rape Plants . . 15

Correlation for Pairs of Fatty Acids Expressed as

Per Cent of Total Acids . . . . . . . 15

Correlation for Pairs of Fatty Acids Expressed as Per

Cent of Seed ................ 18

Correlation for Oil as Per Cent of Seed and Fatty

Acids as Per Cent of Total Acids . . . . . . 18

Correlation for Oil and Fatty Acids as Per Cent of

Seed ................. 18

DISCUSSION ...................... 20

Preliminary Data ............. 20

Relation of a Fatty Acid to the Whole Seed ..... 21

Interpretation of Correlation ......... 23

Correlation for Pairs of Fatty Acids Expressed as

Per Cent of Total Acids ........... 27

Correlation for Pairs of Fatty Acids Expressed as

Per Cent of Seed . . . . . . . . . 28

Correlation for Oil as Per Cent of Seed and Fatty

Acids as Per Cent of Total Acids . . . . . 30 
(iii)

PAGE

Correlation for Oil and Fatty Acids as Per Cent of Seed . . . . . . . . . . . . . 31

Correlation for Values of the Same Variate Measured by Two Expressions . . . . . . . . . 34 SURMARY AND CONCLUSIONS ............. 37 IITERATURE CITED . . . . . . . . . . . 40 


\section{LIST OF TABLES}

TABLE

PAGE

1. Correlation Coefficients for Pairs of Fatty Acids . . . . . . . . . . . .

2. Fatty Acids as Per Cent of Total Acids and Oil as Per Cent of Seed for Ten Individual Rape Plants ... . . . . . . . . .

3. Fatty Acids as Per Cent of Seed and Oil as Per

Cent of Seed for Ten Individual Rape Plants . . 14

4. Means and Standard Deviations for Oil Content of Seed and Fatty Acid Components of Oil for Four Populations of Rape Plants . . . . . 16

5. Correlation Coefficients for $\mathrm{O} i \mathrm{l}$ and Fatty Acids and for Pairs of Fatty Acids from Four Populations of Rape Plants . . . . . . . 17

6. Correlation Coefficients for the Values of Individual Fatty Acids Expressed as Per Cent of Total Fatty Acids and as Per Cent of Seed .................. 


\section{ACKNOWLEDGMENTS}

Grateful acknowledgments are made to Professor R. C. MeGinnis for suggesting the project and to Professors L. H. Shebeski, F. W. Hougen and A. K. Storgaard for encouragement, guidance and helpful suggestions. 


\begin{abstract}
CORRELATIONS INVOLVING OIL AND FATTY

ACIDS IN RAPESEED
\end{abstract}

\title{
Baldur Rosmund Stefansson
}

Associated variation for seed oil and its fatty acid components was investigated using seed from four populations of rape plants. Fatty acids were measured as per cent of total fatty acids and as per cent of seed. Correlation coefficients were calculated for the five pairs of fatty acids measured by the two expressions and for oil and each of the fatty acids measured by the two expressions.

The correlation coefficients for fatty acids expressed as per cent of total acids were essentially similar to published correlation coefficients. The coefficients for fatty acids expressed as per cent of seed were quite different. The differences between these correlation coefficients were attributed to a large component of mathematical origin which occurs in correlation coefficients calculated from fatty acids expressed as per cent of total fatty acids or oil. This component was largely eliminated from correlation coefficients calculated from fatty acids expressed as per cent of seed. Thus, correlation coefficients for fatty acids based on seed provide a better estimate of actual relations in plants than those based on total fatty acids or oil. 


\section{INTRODUCTION}

Vegetable oils are an important human food. Although vast areas of land were available, practically no edible vegetable oil seeds were produced in Canada until. World War II when a shortage of fats and oils stimulated trial of several kinds of plants as potential oil crops. Plot and field scale trials made during World War II led to increased production. Recently Canadian edible oil seed production has become quite substantial. In 1964, edible oil seed crops, principally soybeans, sunflowers, and the annual rapes, occupied a million acres of land and approximately a billion pounds of edible oil seeds were produced $(4)$. In 1965, Canadian rapeseed production was estimated at 1.14 billion pounds $(4)$ indicating that the annual rapes have becone the most important source of edible vegetable oil in Canada.

The acceptability of a vegetable oil for edible or industrial purposes is determined by its fatty acid composition. Oils high in linoleic, linolenic or erucic acid are valued for industrial uses. Oils high in oleic and linoleic, but low in linolenic and erucic are favored for edible purposes. Unfortunately all commercially available rapeseed oils which are used primarily for edible purposes contain substantial quantities of linolenic and erucic acid. 
Several authors $(5,9,31)$ have suggested that the quality of rapeseed oil as an edible oil would be improved if the erucic and linolenic acid components were eliminated from the oil. Considerable progress has been made toward the production of rape varieties with seed oils practically free from erucic acid $(5,31,32)$ but relatively little progress has been made toward eliminating linolenic acid.

Interest in correlation coefficients for pairs of fatty acids and for oil and fatty acids was stimulated by lack of knowledge concerning the inheritance of oleic, linoleic and linolenic acid content in rapeseed and by the difficulty of interpreting some of the published correlation coefficients for pairs of fatty acids in a manner consistent with knowledge of synthesis and accumulation of fatty acids and oil in developing seeds.

This study was undertaken to clarify the interrelationships of rapeseed oil and its fatty acid components. Correlation coefficients calculated from fatty acids expressed in the traditional manner, as per cent of total fatty acids, were compared and contrasted with coefficients calculated from the sane data with fatty acids expressed as per cent of seed. 


\section{LITERATURE REVIEW}

Correlation measures the associated variation of two or more variables but usually provides little information concerning the causes of associated variation. Ideally, correlation should serve to bring together and unify knowledge which might otherwise be regarded as unrelated information. The correlation coefficients for pairs of fatty acids from seed oils have not always served this purpose. More complete arrays of correlation coefficients and more knowledge of the variates correlated appear to be needed. The variation in the fatty acid composition of seed oils, the synthesis of fatty acids, and the sequence in which the fatty acid components of the oil are accumulated in the developing seeds are reviewed to provide information for interpreting correlation coefficients for pairs of fatty acids and for oil and fatty acids.

The fatty acid composition of seed oils from oil crops has been regarded as a relatively fixed characteristic of each species (10). McNair (21) stated that "the properties of a vegetable oil of any plant in any part of the world can be foretold from two factors, its place in the botanical system and its climatic source."

More extensive investigation within groups led to the discovery of genetically conditioned, extreme variations in the major constituents of the seed oils of safflower (II) and rape (32). Several publications have been written on the 
inheritance of the major constituents of safflower and rape seed oils $(5,7,9,11,16,17,18)$; major differences for pairs of fatty acids are conditioned by one or two gene loci.

The range of variation in the degree of unsaturation for rape $(5,19,31)$ and soybean $(12,15,34)$ seed oils, which is directly related to variation in oleic, linoleic, and linolenic acid content, appears to be rather limited. Evidently, the frequency of extreme variants is low. The genes conditioning oleic and linoleic acid content in safflower seed oil act in a dominant manner; the linoleic acid value for the hetero zygote is high $(16,17)$. If the genes conditioning degree of unsaturation in rape and soybean seed oils also act in a dominant manner it would be relatively difficult to isolate the highest and lowest degrees of unsaturation that may exist within various populations. Environmental effects, which exert considerable influence on the degree of unsaturation, also tend to obscure genetic differences. High positive correlation coefficients $(12,19,34)$ for linoleic and linolenic acid contents of seed oils may be an indication of limitation to possibilities for variation. The correlation between linoleic and linolenic acid content in soybean oil has been interpreted to mean that it would be difficult to reduce the linolenic acid content of the oil without encountering a corresponding decrease in linoleic acid content (15). 
The sequence in which fatty acids, such as oleic, linoleic and linolenic are derived from each other has been discussed by several authors. Hilditch (10) favors the hypothesis that oleic and linoleic are derived from linolenic (or precursor) by a process of saturation. However, evidence which indicates that linoleic and linolenic are derived from oleic by desaturation $(1,13,20,27)$ has been accumulating. Simmons

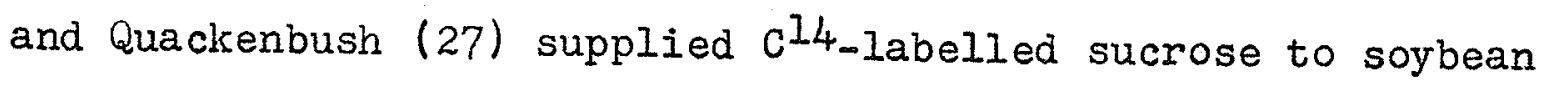
stems bearing pods and leaves. The order in which radioactivity appeared in the fatty acids strongly favored the conversion of oleic acid to linoleic and then to linolenic acid. Canvin (1) supplied acetate-1-C 14 to developing seeds of flax, rape, and safflower in short term kinetic experiments. Oleic acid was the first long-chain fatty acid to become radioactive and appeared to be the precursor of other unsaturated fatty acids in these oils. In flax (1), the fatty acids appeared to be formed in the sequence oleic, linoleic and linolenic. In rape, oleic acid appeared to be the precursor of the other unsaturated acids by two different pathways. In one instance, by chain lengthening, it led to eicosenoic acid and then to erucic acid. In the other instance, it led to linoleic acid by desaturation. The saturated fatty acids appeared to be derived by a pathway independent of that leading to oleic acid. Similar results were reported by Downey and Craig (6) who found that oleic acid was converted to eicosenoic and then to erucic acid by the successive addition of two acetate molecules to the carboxyl end of the fatty acid. 
Several reports $(26,28,29)$ indicate that the rate at which a particular fatty acid is accumulated in developing seeds varies with the stage of development. The fatty acid composition of the oil also varies with the stage of development. Simmons and Quackenbush (26) determined the fatty acid composition of oil and oil content of seed from two varieties of soybeans from 23 to 67 days after flowering. The amounts (actual weight) of saturated, oleic, Iinoleic and linolenic acids in the seed increased continuously. The linolenic acid percentage of the oil (relative amount) was high at early stages and decreased toward maturity while the linoleic acid percentage increased continuously until the fiftieth day, then remained constant. Sims et al. (29) determined the quantities of fatty acids accumulated in flax and safflower seeds from 10 to 40 or 50 days after fertilization. In flax the quantities of the fatty acids oleic, linoleic and linolenic increased continuous1y. During the short hot growing season of 1955, Raja flax developed much less linolenic than it did in 1956. In safflower, the quantities of oleic and linoleic increased continuously until 30 days after fertilization. After this date more Iinoleic was accumulated under favorable conditions of moisture and temperature, and more oleic under less favorable conditions. Sims (28) determined the fatty acid composition of rape and crambe seed oils at $7,14,21$ and 42 or 56 days after fertilization. The percentages of palmitic, stearic and linoleic, 
relatively high at seven days, decreased as development took place. The percentages of linolenic were relatively constant. The percentage of erucic acid increased continuously after it was first detected 14 days after fertilization; this increase was accompanied by a decrease in the percentage of oleic. In rapeseed oil free from erucic acid the percentage of oleic acid increased continuously.

A number of correlation coefficients for pairs of fatty acids from seed oils have been reported $(3,6,12,19$, 34). These coefficients, which are summarized in Table 1, were calculated from fatty acids measured as per cent of total fatty acids or as per cent of oil. Löof and Appelqvist (19) did not report the sign, plus or minus, for the correlation coefficients for oleic and other fatty acids. The correlation coefficients for oleic and erucic were negative and high; those for linoleic and linolenic were positive and ranged from low to high with a predominance of high values. 
TABLE 1. CORRELATION COEFFICIENTS FOR PAIRS OF FATTY ACIDS

$\left.\begin{array}{llcc}\hline \hline \text { Fatty acids correlated } & \text { Source of oil } & \begin{array}{c}\text { Correlation } \\ \text { coefficient }\end{array} & \text { Authors } \\ \hline \text { Oleic and erucic } & \text { Summer rape } & -.975 & \text { Craig, 1961 } \\ \text { Oleic and erucic } & \text { Summer rape } & -.99 & \text { Downey and Craig, 1964 } \\ \text { Oleic and linoleic } & \text { Summer rape } & .6605 \\ \text { Oleic and linoleic } & \text { Winter rape } & .1002 \\ \text { Oleic and linolenic } & \text { Summer rape } & .8797 \\ \text { Oleic and linolenic } & \text { Winter rape } & .0139 \\ \text { Linoleic and linolenic } & \text { Summer rape } & +.8323 \\ \text { Linoleic and linolenic } & \text { Winter rape } & +.5715\end{array}\right]$ Löf and Appelqvist, 1964




\section{MATERIALS AND METHODS}

The strains of rape (Brassica napus $L_{0}$ ) used in this study were derived from the variety Liho by selection for oil with low erucic acid content at the University of Manitoba (3I). Seed oils from the two strains, $P_{1}$ and $P_{2}$, which were practically free from erucic acid, differed mainly in oleic and linoleic acid content; the two fatty acids were the major constituents of these seed oils (Table 4).

The populations of rape used in this study were originally intended for a study of the inheritance of linoleic acid content (18). $P_{1}$ and $P_{2}$ were populations of individual plants from two parents and, $\mathrm{BC}_{1}$ and $\mathrm{BC}_{2}$, populations of $\mathrm{F}_{1}$ plants from backcrosses to $P_{1}$ and $P_{2}$ respectively. These populations were grown in the field as a solid stand in rows spaced one foot apart. Ten rape plants grown in the greenhouse were also used in this study. Mature open-pollinated and self-pollinated seeds were collected from individual plants taken from these populations.

Oil content of the seed was determined by the method described by Troeng (33). One-gram samples of seed were used. Open-pollinated seed was used since pollen source does not influence oil content (22). Oil content was expressed as per cent of the dry weight of the seed.

The fatty acid composition of the oil was determined by gas chromatography. A Carver press was used to extract the 
oil for gas chromatographic analyses. The samples of selfpollinated seed, not less than 20 seeds and usually more than 50 seeds, were placed in a Carver test cylinder and pressed at 1150 p.s.i. for 15 seconds. The crushed seed and oil were washed with petroleum ether (Skellysolve F, Skelly Oil Co., Kansas City) from the cylinder into a vial and allowed to stand for at least one hour. The oil and Skellysolve $F$ were decanted into $30 \mathrm{ml}$. flasks with bottoms drawn to a point. To produce methyl esters of the fatty acids, $5 \mathrm{ml}$. of $0.02 \mathrm{~N}$ solution of sodium methylate in methanol were added, and followed by refluxing, for ten minutes. After refluxing the methyl ester solution was neutralized by adding $5 \mathrm{ml}$ of an $0.02 \mathrm{~N}$ solution of acetic acid in petroleum ether. The solution was washed with $30 \mathrm{ml}$. distilled water and finally the Skellysolve $F$ was evaporated from the solution leaving the methyl esters. A Beckman GC-2A gas chromatographic unit equipped with a Philips strip chart recorder was used to determine the composition of the methyl esters. Areas of gas chromatographic peaks were determined by the use of a Philips integrator incorporated into the recorder.

Column specifications:

Tube - copper, 36 in. long, $3 / 16$ in. O.D.

Solid phase - 40-50 mesh firebrick, 6 parts (wt.)

Liquid phase - diethyleneglycolsuccinate, I part (wt.)

Column temperature $-193^{\circ} \mathrm{C}$.

Carrier gas - helium. Pressure was adjusted with each column to give a total retention time of 20 minutes for each sample. 
The areas of the peaks were used to calculate fatty acids as per cent of total fatty acids. The quantities of the fatty acids palmitic, oleic, linoleic, linolenic and eicosenoic were determined but not those of minor constituents present in amounts less than one per cent. Fatty acids, expressed as per cent of the seed, were calculated by multiplying fatty acids expressed as per cent of total fatty acids, oil content and a constant. This constant 0.957 was used to convert fatty acid percentages based on total fatty acids to fatty acid percentages based on total oil. 


\section{RESULTS}

\section{Preliminary Data}

The fatty acid compositions of seed oils from ten individual rape plants expressed as per cent of total acids (Table 2) and as per cent of seed (Table 3) serve as an example of data from the same plants expressed in terms of oil and in terms of seed.

The means and standard deviations which follow provide estimates of variability due to analytical procedures. The means and standard deviations for 24 analyses of one sample of rapeseed oil performed at intervals during several months, expressed as per cent of total acids, were: palmitic 3.30 and 0.31 , oleic 35.4 and 2.29 , linoleic 19.7 and 1.2 , linolenic 9.7 and 0.95 , eicosenoic 11.7 and 0.86 , and erucic 20.2 and 2.00. The mean and standard deviation for 47 analyses of one sample of rapeseed performed at intervals during several months were 46.3 and 0.26 per cent oil, respectively. 
TABLE 2. FATTY ACIDS AS PER CENT OF TOTAL ACIDS AND OIL AS PER CENT OF SEED FOR TEN INDIVIDUAL RAPE PLANTS

\begin{tabular}{cccccccc}
\hline \hline \multirow{2}{*}{$\begin{array}{c}\text { Plant } \\
\text { number }\end{array}$} & $\begin{array}{l}\text { Oil as } \\
\text { per cent } \\
\text { of seed }\end{array}$ & \multicolumn{6}{c}{ Fatty acids as per cent of total acids } \\
\cline { 2 - 8 } 1 & 43.1 & 5.0 & 54.8 & 27.3 & 11.4 & 1.6 & 82.1 \\
2 & 40.1 & 5.1 & 54.2 & 25.7 & 13.0 & 1.7 & 79.9 \\
3 & 40.1 & 5.7 & 48.7 & 30.8 & 12.7 & 2.1 & 79.5 \\
4 & 40.0 & 5.0 & 52.4 & 27.8 & 13.2 & 1.7 & 80.2 \\
5 & 39.9 & 5.1 & 51.4 & 28.0 & 13.4 & 2.1 & 79.4 \\
6 & 34.9 & 7.0 & 41.2 & 35.9 & 13.5 & 2.3 & 77.1 \\
7 & 33.9 & 5.8 & 47.9 & 32.1 & 12.7 & 1.5 & 80.0 \\
8 & 31.1 & 5.9 & 44.6 & 35.8 & 12.4 & 1.3 & 80.4 \\
9 & 30.0 & 6.7 & 43.9 & 35.5 & 11.8 & 1.9 & 79.4 \\
10 & 29.3 & 6.6 & 42.6 & 35.5 & 13.3 & 2.0 & 78.3 \\
\hline \hline
\end{tabular}


TABLE 3. FATTY ACIDS AS PER CENT OF SEED AND OIL AS PER CENT OF SEED FOR TEN INDIVIDUAL RAPE PLANTS

\begin{tabular}{cccccccc}
\hline \hline \multirow{2}{*}{$\begin{array}{c}\text { Plant } \\
\text { number }\end{array}$} & $\begin{array}{c}\text { Oil as } \\
\text { per seed }\end{array}$ & \multicolumn{6}{c}{ Fatty acids as per cent of seed } \\
\cline { 2 - 8 } 1 & 43.1 & 2.1 & 22.6 & 11.3 & 4.7 & 0.7 & 33.9 \\
2 & 40.1 & 2.1 & 20.8 & 9.9 & 5.0 & 0.7 & 30.7 \\
3 & 40.1 & 2.2 & 18.7 & 11.8 & 4.9 & 0.8 & 30.5 \\
4 & 40.0 & 1.9 & 20.1 & 10.6 & 5.1 & 0.7 & 30.7 \\
5 & 39.9 & 1.9 & 19.6 & 10.7 & 5.1 & 0.8 & 30.3 \\
6 & 34.9 & 2.3 & 13.8 & 12.0 & 4.5 & 0.8 & 25.8 \\
7 & 33.9 & 1.9 & 15.5 & 10.4 & 4.1 & 0.5 & 25.9 \\
8 & 31.1 & 1.8 & 13.3 & 10.7 & 3.7 & 0.4 & 24.0 \\
9 & 30.0 & 1.9 & 12.6 & 10.2 & 3.4 & 0.5 & 22.8 \\
10 & 29.3 & 1.9 & 11.9 & 10.0 & 3.7 & 0.6 & 21.9 \\
\hline
\end{tabular}


Characteristics of Four Populations of Rape Plants

The means and standard deviations for oil and fatty acids from the four populations of rape plants (Table 4 ) indicate that all populations were somewhat similar. Within each population, means and standard deviations for fatty acids tended to vary together; the ranks for both were the same (oleic 1 , linoleic 2 , linolenic 3, palmitic 4, and eicosenoic 5) within all populations.

Seed oils from the parents, $P_{1}$ and $P_{2}$, differed in oleic and linoleic acid content. The standard deviations for these two fatty acids were somewhat higher for the backcross populations, $\mathrm{BC}_{1}$ and $\mathrm{BC}_{2}$, than for the parental populations, $\mathrm{P}_{1}$ and $\mathrm{P}_{2}$. This was expected because the backcross populations were more heterozygous than the parental populations.

Correlation for Pairs of Fatty Acids Expressed as Per Cent of Total Acids

When the expression fatty acids as per cent of total fatty acids was used to measure the variates (Table 5), there were three high or fairly high, consistent negative correlation coefficients for pairs of fatty acids for the four populations; these were: palmitic and oleic, -0.430 to -0.712 ; oleic and linoleic, -0.848 to -0.979 , and oleic and linolenic, -0.581 to -0.698 . There were positive coefficients for palmitic and linoleic, 0.341 to 0.529 , and for linoleic and linolenic, 0.309 to 0.545 . Correlation coefficients for palmitic and linolenic, and for eicosenoic and each of the other four fatty acids were inconsistent or low in magnitude. 
TABLE 4. MEANS AND STANDARD DEVIATIONS FOR OIL CONTENT OF SEED AND FATTY ACID COMPONENTS OF OIL FOR FOUR POPULATIONS OF RAPE PLANTS

\begin{tabular}{llllllllll}
\hline & $P_{1} n=24$ & $P_{2}$ & $n=16$ & $B C_{1}$ & $n=88$ & $B_{2} n=58$ \\
\hline & Mean & S. D. & Mean & S. D. & Mean & S. D. & Mean & S. D. \\
\hline Oil (per cent of seed) & 34.8 & 1.76 & 35.3 & 1.22 & 34.3 & 2.50 & 35.3 & 2.30
\end{tabular}

Fatty acids as per cent of total fatty acids

\begin{tabular}{|c|c|c|c|c|c|c|c|}
\hline $\begin{array}{l}\text { Oleic } \\
\text { Linoleic } \\
\text { Linolenic } \\
\text { Eicosenoic } \\
\text { Palmitic }\end{array}$ & $\begin{array}{r}54.6 \\
29.0 \\
9.1 \\
1.6 \\
5.7\end{array}$ & $\begin{array}{l}3.17 \\
2.06 \\
1.00 \\
0.55 \\
0.72\end{array}$ & $\begin{array}{r}46.0 \\
36.1 \\
10.5 \\
1.6 \\
5.8\end{array}$ & $\begin{array}{l}4.10 \\
3.38 \\
0.96 \\
0.29 \\
0.66\end{array}$ & $\begin{array}{r}50.7 \\
32.0 \\
10.4 \\
1.3 \\
5.6\end{array}$ & $\begin{array}{l}4.23 \\
2.90 \\
1.14 \\
0.48 \\
0.84\end{array}$ & $\begin{array}{r}47.7 \\
34.6 \\
10.4 \\
1.4 \\
6.0\end{array}$ \\
\hline
\end{tabular}

Fatty acids as per cent of seed

$\begin{array}{lrrrrrrrr}\text { Oleic } & 18.2 & 1.91 & 15.6 & 1.85 & 16.7 & 2.30 & 16.2 & 2.26 \\ \text { Linoleic } & 9.7 & 0.47 & 12.2 & 0.85 & 10.4 & 0.82 & 11.7 & 1.07 \\ \text { Linolenic } & 3.0 & 0.29 & 3.6 & 0.31 & 3.4 & 0.36 & 3.5 & 0.34 \\ \text { Eicosenoic } & 0.5 & 0.17 & 0.5 & 0.11 & 0.4 & 0.16 & 0.5 & 0.20 \\ \text { Palmitic } & 1.9 & 0.22 & 2.0 & 0.21 & 1.8 & 0.21 & 2.0 & 0.23\end{array}$


TABLE 5. CORRELATION COEFFICIENTS FOR OIL AND FATTY ACIDS AND FOR PAIRS OF FATTY ACIDS FROM FOUR POPULATIONS OF RAPE PLANTS

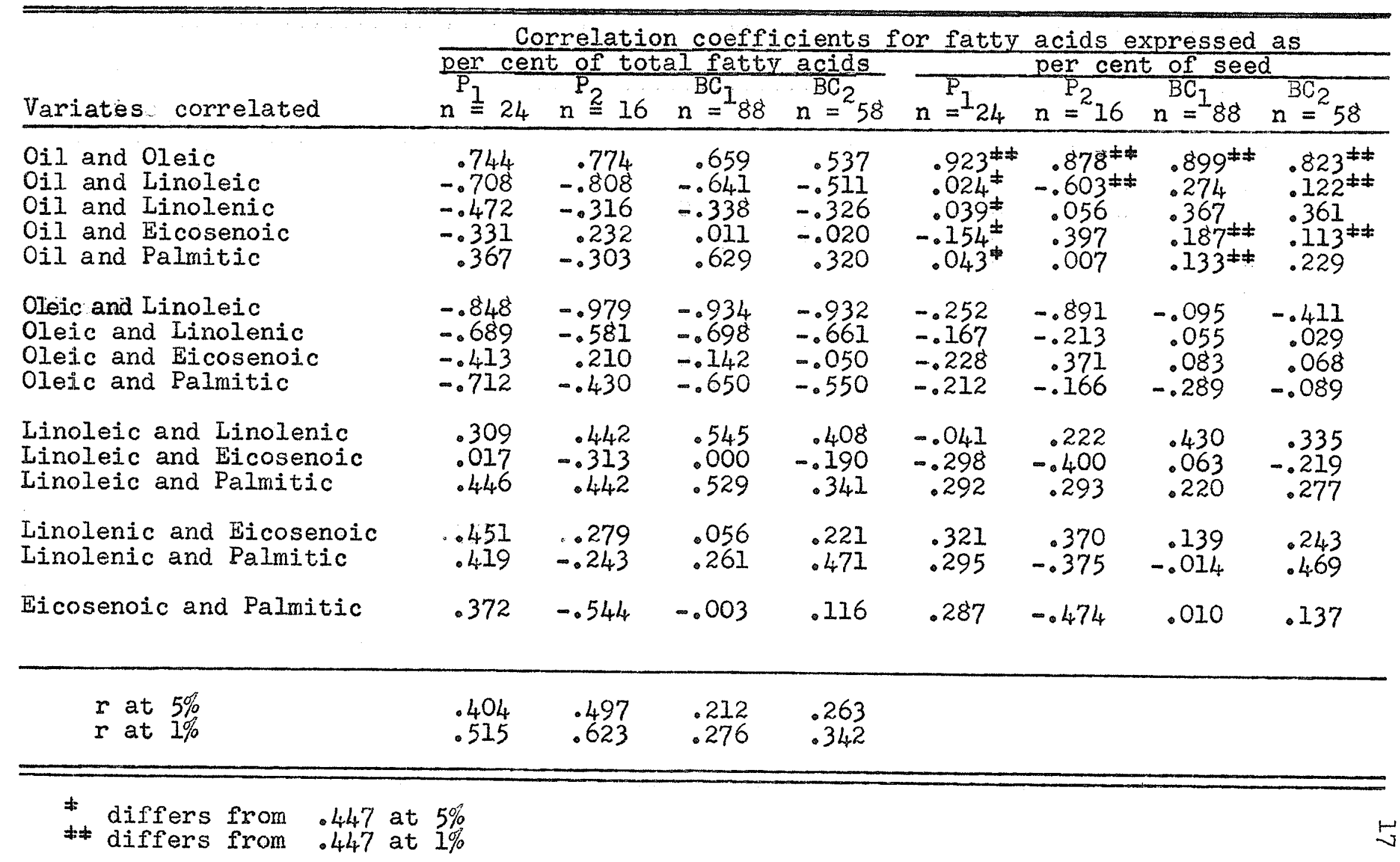


Correlation for Pairs of Fatty Acids Expressed as Per Cent of

Seed

When the expression, fatty acids as per cent of seed, was used to measure the variates, there were no consistent high correlation coefficients for any pair of fatty acids (Table 5). The four coefficients for oleic and linoleic were negative; the one for $P_{2}$ was high, -0.891 , and the one for $B_{2}$ somewhat lower, -0.411 ; the other two did not differ significantly from zero.

Correlation for Oil as Per Cent of Seed and Fatty Acids as Per Cent of Total Acids

When the expressions, oil as per cent of the seed, and fatty acids as per cent of total fatty acids, were used to measure the variates, 11 of the 20 correlation coefficients for oil and fatty acids were negative (Table 5). The four correlation coefficients for oil and oleic were consistently high and positive, 0.537 to 0.774 ; those for oil and linoleic consistently high and negative, -0.511 to -0.808 ; those for oil and linolenic somewhat lower and negative, -0.316 to -0.472 , and the coefficients for oil and each of palmitic and eicosenoic generally low and inconsistent.

Correlation for Oil and Fatty Acids as Per Cent of Seed When the expressions, oil as per cent of the seed, and fatty acids as per cent of the seed, were used to measure the variates, 18 of the 20 correlation coefficients for oil 
and fatty acids were positive in sign (Table 5). Most of the associations were low and somewhat inconsistent. One of the four correlation coefficients for oil and linoleic was negative and high, -0.603 ; the other three were positive and low. The four coefficients for oil and oleic, 0.823 to 0.923 ; were higher than those for the same variates when oleic was measured as per cent of total fatty acids. 


\section{DISCUSSION}

Preliminary Data

The fatty acid compositions of seed oils for ten individual rape plants expressed as per cent of total acids (Table 2) and as per cent of seed (Table 3) serve to illustrate the type of information that becomes available when fatty acids are expressed in terms of oil and in terms of seed. A positive association between oil content of the seed and oleic acid percentage is apparent in both tables. A negative association between linoleic and oil is apparent in Table 2 but little or no association between the two is evident in Table 3. A negative association between oleic and linoleic is clearly apparent in Table 2 but not evident in Table 3. These apparently contradictory results led to an examination of the sums for oleic and linoleic which were relatively constant when fatty acids were expressed as per cent of total acids (Table 2); to a consideration of the relation of a fatty acid to the whole seed, and a discussion of the difficulty of interpreting correlation coefficients for attributes of plants. This was done in an effort to interpret similar results which were obtained from larger populations of plants. When fatty acid composition is expressed in terms of oil and seed (Tables 2 and 3) the fatty acid composition of the oil can be related to events which occur in the seed. The high linoleic acid percentages, such as 35.5 per cent for plant 10 
(Table 2), were not accompanied by high linoleic percentages in the seed but were the result of low oleic acid and oil percentages in the seed.

\section{Relation of a Fatty Acid to the Whole Seed}

A fatty acid component of the oil may be considered in terms of its relation to the whole seed. On this basis, variation in fatty acid composition may be placed into three general groups: substitution of one fatty acid for another (Group 1); substitution of one fatty acid for some non-oil component or components of the seed (Group 2); and changes in the weight of one fatty acid which are not accompanied by corresponding changes in the weight of other components of the seed (Group 3). The three types of variation may occur together and it may be rather unusual for only one to occur alone.

A fatty acid may substitute for equivalent quantities of another fatty acid or acids (Group 1). The genetically conditioned reversal in quantities of oleic and linoleic acids in safflower seed oil (II) and similar genetically controlled changes in oleic and erucic acids in rapeseed oil (3I) are examples of this kind of substitution. Environmentally conditioned reversals would include similar inverse changes in the quantities of oleic and linoleic acids in sunflower seed oil induced by changes in temperature (2). 
A fatty acid may substitute for a non-oil fraction of the seed such as protein or carbohydrate (Group 2). The amount of nitrogen available to the developing seed may influence the relative proportions of oil and protein which are accumulated in the seed (2). Negative associations $(2,15)$ and negative correlations $(15,25)$ that have been reported for oil and protein content of seed are cited as evidence for the occurrence of this kind of relationship.

Changes in the weight of one fatty acid which are not accompanied by corresponding changes in the weight of other components of the seed will be associated with changes in seed weight (Group 3). In flax, seed size may be influenced by a number of environmental factors such as temperature $(2,8)$, photoperiod (30), cool wet versus hot dry conditions (23), and by the hereditary influence of varieties (14) during the period from flowering to maturity. Similar reactions to temperature have been reported for rape $(2,25)$. In all these cases, the length of the period from flowering to maturity was positively associated with seed size and oil content. Positive association of oil content and seed size, which generally occurred in these studies, implies that variations in at least some of the fatty acid components of the oil are associated with variation in seed weight.

The environmental factors which favored development of high oil content in flax and rape seed also favored the production of the more highly unsaturated and, in rapeseed, the longer 
chain fatty acids. The tendency for favorable conditions to increase the production of fatty acids derived from oleic acid probably involves substitution of one fatty acid for another (Group 1). In this connection it may be of interest to note that when variation in seed size of flax was due to varieties (heredity), oil content and seed size were highly correlated $(r=0.716$ and 0.778$)$ but oil content and iodine number were not significantly correlated (14). This contrast appears to be a difference in the effect of environmental and genetic factors on association between oil content and fatty acid composition.

Interpretation of Correlation

Interpretation of correlation between two attributes of a plant is difficult because a plant is a single functional unit. Two attributes of a plant may be correlated because both are associated with a third attribute which may be unknown. The expected value for a correlation coefficient, based on random distribution, may deviate from zero because the two correlated variates may be a part and a sum which includes the part or they may be parts of a sum which becomes a constant when the parts are measured as per cent. The rules for coding variates used in calculating correlation coefficients may be violated when the two variates are measured in different but commonly used units of measurement. 
The spurious correlation which is often obtained for a time series is cited as an example of correlation between two variates which occurs because both are correlated with a third variate $(24)$. Because a plant is a single functional unit, any two attributes of a plant are in some way related to other parts of the plant. It would be very difficult or impossible to measure the amount of photosynthate which is avajlable for the production of oil. However, this variable probably exerts a direct influence on variations in oil content and the fatty acid composition of the oil.

The seed oil from the rape plants used in this study may be regarded as the sum of five fatty acid constituents and a glycerol component. Therefore, high, positive correlation coefficients could be expected for the absolute amounts of each fatty acid and oil. Each fatty acid is an element common to itself and oil, while the other fatty acids are the different parts of the oil. If the parts (i.e. fatty acids) which make up the sum (oil) are random samples from the same normal population, the expected population values for part-whole correlation of this type which may be considered as a special case of common elements $(24)$ are given by the following formula:

$$
P=n_{12} / \sqrt{n_{1} n_{2}}=1 / \sqrt{5 \times 1}=0.447
$$

( $n_{12}$ is the number of common elements and $n_{1}$ and $n_{2}$ the total number of elements in each of the two variates.) In substituting actual values in the formula, the glycerol fraction was 
not used since it may be regarded as a constant fraction of the oil. Thus, the oil was regarded as five elements and each of the fatty acids as one.

The means and standard deviations for the five fatty acids in the four populations of rape (Table 4) indicate that the five fatty acids cannot be regarded as representatives of the same normal population. For example, it would be difficult to believe that the mean of 18.2 with a standard deviation of 1.91 for oleic acid and the mean of 1.9 with a standard deviation of 0.22 for palmitic acid in the $P_{1}$ population were derived by sampling from the same population of fatty acids. Bartlett's test of homogeniety of variance (24) was used to test the variances of the five fatty acids from the four populations of rape. Differences between the variances for the different fatty acids were highly significant; therefore, the expected value of 0.447 for the part-whole correlation is not applicable in this case. No formula is available for calculating the expected value for a part-whole correlation if the parts which make up the sum are drawn from different populations. Thus, while positive correlation coefficients for oil and fatty acids are expected on the basis of chance alone, the expected value for each one is not available.

If the sum of two variables, $X$ and $Y$, is a constant, then $X$ and $Y$ will be correlated with $r=-1.0$. This type of correlation, which is a result of the restriction in the degrees 
of freedom imposed on $X$ and $Y$ by the restriction that the sum of the two is equal to a constant, will be referred to as correlation due to restriction in freedom of variation for variates whose sum is a constant. When fatty acids are measured in the traditional manner as per cent of total fatty acids or oil, total fatty acids or the oil is regarded as a constant, and is the sum of the fatty acids or the sum of the fatty acids and the glycerol fraction. This introduces a strong tendency for negative association for pairs of fatty acids. High negative correlation for the major fatty acid constituent of the oil and each of two other fatty acids, $A$ and $B$, may even lead to a spurious positive correlation for $A$ and $B$. This tendency for correlation due to restricted freedom for variation may be alleviated or eliminated by expressing the fatty acids as per cent of the seed; then the sum of the fatty acids will not be a constant.

The rules for coding variates used in the calculation of correlation coefficients are violated when correlation coefficients are calculated from oil expressed as per cent of the seed and fatty acids as per cent of total fatty acids or as per cent of oil. In this case, oil is a coded value of actual weight in terms of seed while fatty acids are coded values of actual weights in terms of oil. A spurious component of variable magnitude is introduced into the correlation because oil is not a constant fraction of the seed. This difficulty 
can be eliminated by expressing both oil and fatty acids as per cent of the seed; then all variates are coded values of actual weights in terms of seed.

Correlation for Pairs of Fatty Acids Expressed as Per Cent of Total Acids

When fatty acids were expressed as per cent of total fatty acids most of the correlation coefficients for oleic and other fatty acids were negative while those for linoleic and linolenic were positive (Table 5). A similar general trend is also apparent for the published correlation coefficients listed in Table I. As previously outlined, the expression used to measure the fatty acids restricts freedom for variation among fatty acids and introduces a strong tendency for negative associations. The high negative correlation coefficients (Table 5) for oleic and each of linoleic and linolenic (-0.581 to -0.979 ) suggest that the positive coefficients for linoleic and Iinolenic $(0.309$ to 0.545$)$ might be caused by the correlation of both with oleic. The partial correlation coefficients for linoleic and linolenic on oleic which were $-0.717,-0.765$, -0.385 and -0.765 for $P_{1}, P_{2}, B_{1}$, and $B_{2}$ respectively, provide evidence that the positive simple correlation coefficients were caused by correlation with oleic. Although the positive correlation for linoleic and Innolenic observed in this study could be explained by the negative correlation of both with oleic, this explanation does 
not account for all positive associations between the two. For example, the partial correlation coefficient for linoleic and linolenic on oleic, 0.704 , which was calculated from Lööf and Appelqvist's data for summer rape (19), is quite similar to the simple correlation coefficient which was 0.832 . In soybeans, correlation coefficients of -0.437 and -0.669 have been reported for maximum temperature and each of linoleic and linow lenic, respectively (12). Thus, environmental factors which influence both linoleic and linolenic in a similar manner may be an important cause for positive association between the two fatty acids.

\section{Correlation for Pairs of Fatty Acids Expressed as Per Cent of} Seed

When associated variation for fatty acids was considered in terms of seed, that is, when fatty acids were expressed as per cent of the seed, there were no consistent significant correlation coefficients for any pair of fatty acids in the four populations of rape (Table 5). The consistent negative correlation coefficients which resulted from restricting the freedom for variation among fatty acids by making the sum equal to a constant were essentially eliminated by measuring fatty acids in terms of seed. The occasional significant correlation, such as the negative one, -0.891 , for oleic and linoleic in $\mathrm{P}_{2}$ was interpreted to mean that associations, 
perhaps linkages, between fatty acid components do occur in certain populations but generally each fatty acid tends to vary independently of others.

Since the fatty acids varied essentially independently of each other, associations among fatty acids do not appear to constitute a serious obstacle to major changes in fatty acid composition. However, Hilditch (10) in a survey of the fatty acid composition of seed oils noted that the presence of linolenic acid is always accompanied by appreciable quantities of oleic and linoleic, and that erucic is accompanied by significant quantities of olej.c andeicosenoic. This suggests that the manner in which other fatty acids are derived from olejc acid by desaturation $(1,13,20,27)$ and by a carbon chain lengthening process $(1,6)$ may serve to limit variation. The presence of the first (oleic) and second (Iinoleic and eicosenoic) members of each sequence is not always found to be accompanied by the third (Iinolenic and erucic) but the presence of the third is practically always accompanied by appreciable quantities of the first and second.

High negative correlation coefficients such as those for oleic and linolenic $(-0.581$ to -0.698$)$ obtained when fatty acids were measured as per cent of total fatty acids practically disappeared $(0.055$ to -0.213$)$ when fatty acids were measured in terms of seed (Table 5). For this reason, it might be interesting to speculate how the high negative correlation 
coefficients $(-0.975$ and -0.990$)$ which have been reported for oleic and erucic (Table I) would be changed if the coefficients for the same populations were recalculated from fatty acids expressed in terms of seed. If the evidence (31) which suggested that major changes in the proportions of the fatty acids, oleic and erucic, were not accompanied by any appreciable change in oil content is correct, then a change in the expression used to measure the variates should have little effect on the correlation coefficients.

\section{Correlation for Oil as Per Cent of Seed and Fatty Acids as}

\section{Per Cent of Total Acids}

As previously outlined, the principles of coding variates used in the calculation of correlation coefficients are violated when one variate is expressed in terms of oil and the other in terms of seed. The high degree of associated variation for pairs of fatty acids expressed as per cent of total acids (Table 5) which resulted from restriction in freedom for variation among fatty acids imposed by making the sum of the fatty acids equal to a constant undoubtedly is reflected in associations of fatty acids and oil. Therefore, at least three effects are confounded in the correlation coefficients for fatty acids as per cent of total acids and oil as per cent of seed; these are: effects due to violation of the principles of coding, effects due to restriction of freedom for variation among fatty acids, and real associations between oil and fatty acids. 
Correlation for Oil and Fatty Acids as Per Cent of Seed

When both oil and fatty acids are measured in terms of seed, 18 of the 20 correlation coefficients for oil and fatty acids are positive in sign (Table 5). The four coefficients for oil and oleic $(0.823$ to 0.923$)$ were higher than those for the same variates when oleic was expressed as per cent of total fatty acids. The single high negative correlation, -0.603 , which represents negative association for oil and linoleic acid in population, $P_{2}$, probably is related to the negative correlation -0.891 for oleic and linoleic in the same population; the partial correlation of oil and linoleic on oleic which was 0.825 provides evidence for such a relationship. The strong tendency for positive association between oil and its fatty acid constituents is expected since each fatty acid contributes to the weight of oil which is the sum of five fatty acids and a glycerol fraction. The expected value of 0.447 for the partwhole correlation was calculated on the assumption that all the fatty acids could be regarded as representatives of the same normal population. When the correlation coefficients for oil and fatty acids expressed as per cent of seed (Table 5) are considered in terms of deviations from an expected value of 0.447 , the coefficients for oleic acid are consistently significantly higher than expected and those for the other four fatty acids consistently lower but not always significantly lower than expected. 
As previously noted, the expected value, 0.447 , is not applicable to the data from this study because the five fatty acids cannot be regarded as samples from the same normal population. For this reason there is a need for a method of calculating the expected value for part-whole correlation in which the parts which make up the sum are not drawn from the same normal population. This need is not restricted to the present study because it is highly probable that parts which make up other sums, such as the components which contribute to yield, also are not representatives of the same normal population. The expected values for this type of correlation probably are in some way proportional to the variation, that is, the variance or standard deviation, for each of the parts which make up the sum.

Since no completely satisfactory method for estimating the correlation between oil and fatty acids which is expected on the basis of chance alone seems to be available, the high positive correlation between oil and oleic (Table 5) was examined further by calculating the correlation coefficients for oleic and oil minus oleic. The oil may be regarded as the surn of five fatty acids and a constant, glycerol, and therefore, these coefficients are the same as those for oleic and the sum of the other four fatty acids. The correlation coefficients were $-0.802,-0.283,-0.275$, and -0.045 for $P_{1}, P_{2}, B C_{1}$, and $\mathrm{BC}_{2}$, respectively. Since these coefficients were negative, the 
high positive correlation coefficients for oil and oleic acid, $0.923,0.878,0.899$ and 0.823 (Table 5), were derived from the contribution that the weight of oleic acid makes to the weight of oil. The correlation coefficients for linoleic and oil minus linoleic, which were $-0.583,-0.238,-0.325$, and -0.056 for $\mathrm{P}_{1}, \mathrm{P}_{2}, \mathrm{BC}_{1}$, and $\mathrm{BC}_{2}$, were quite similar to those for oleic and oil minus oleic. Since there were no substantial corresponding positive correlation coefficients for oil and linoleic acid (Table 5), linoleic acid makes a much less consistent contribution to oil than oleic acid.

Oleic acid, the largest single component of the seed oils from the rape plants used in this study, was much more closely associated with oil content than the other fatty acids (Table 5). This does not imply that the major constituent of other seed oils will necessarily be the one most closely associated with oil content. There were some reasons to expect that oleic would make a more consistent contribution to oil than other fatty acids from the four populations of rape plants used in this study. Mathematically, the variation for oleic acid (Table 4) was larger than the variation for any of the other fatty acids. Since the variation for oleic was a part of the variation for oil, oleic could be expected to be more closely correlated with oil than other fatty acids. Unfavorable environmental factors tend to shift the composition of seed oils from fatty acids such as linoleic and linolenic toward 
oleic. When oleic is the major constituent of a seed oil the possibilities for such a shift will be limited. In addition, when oleic is the major constituent of rapeseed oil, this fatty acid is accumulated in the seed more uniformly throughout the development of the seed than some other fatty acid components of the oil (28). Therefore, environmental factors during any stage of development of the seed could influence both oleic acid and oil content concurrently.

The high positive correlation coefficients for oil and oleic acid (Table 5) imply that oil and oleic acid content might be estimated from each other. There undoubtedly is a tendency for oil and oleic to vary together in populations similar to those used in this study. However, a combination of low oil content and high oleic acid percentage in seed oil from individual plants has occasionally been encountered (unpublished data). These cases were mentioned to indicate that caution should be used if either oil or oleic acid are estimated from each other.

\section{Correlation for Values of the Same Variate Measures by Two}

\section{Expressions}

Correlation coefficients for individual fatty acids measured by the two expressions (e.g. Oleic as per cent of total fatty acids and oleic as per cent of seed) were calculated for the four populations of rape (Table 6). As expected when both oil content and fatty acid composition vary, each correla- 
TABLE 6. CORRELATION COEFFICIENTS FOR THE VALUES OF INDIVIDUAL FATTY ACIDS EXPRESSED AS PER CENT OF TOTAL FATTY ACIDS AND AS PER CENT OF SEED

\begin{tabular}{|c|c|c|c|c|}
\hline \multirow[b]{2}{*}{ Variates } & \multicolumn{4}{|c|}{ Correlation coefficients for } \\
\hline & $\begin{array}{c}P_{1} \\
n=24\end{array}$ & $\begin{array}{c}\mathrm{P}_{2} \\
\mathrm{n}=16\end{array}$ & $\begin{array}{c}\mathrm{BC}_{1} \\
\mathrm{n}=88\end{array}$ & $\begin{array}{c}\mathrm{BC}_{2} \\
n=58\end{array}$ \\
\hline Oleic and Oleic & .933 & .982 & .922 & .920 \\
\hline Linoleic and Iinoleic & .678 & .956 & .466 & .787 \\
\hline Linolenic and Linolenic & .866 & .929 & .747 & .761 \\
\hline Eicosenoic and Eicosenoic & .972 & .984 & .982 & .990 \\
\hline Palmitic and Palmitic & .912 & .954 & .612 & .847 \\
\hline
\end{tabular}


tion coefficient differed somewhat from the others. The extreme values for the 20 coefficients were 0.990 and 0.466 . Since $r^{2}$ for these coefficients was 0.980 and 0.199 , respectively, the meaning of the two expressions with respect to a particular variate may be almost identical but can be quite different. 


\section{SUMWARY AND CONCLUSIONS}

Previous reports of correlation for fatty acids have been accompanied by a minimum of interpretation. In the present study, more complete arrays of correlation coefficients, two expressions to measure the variates, partial correlation, and part-whole correlation were used in an attempt to interpret the associated variation for $0 i l$ and its component fatty acids.

Four populations of rape plants were used in an investigation of the associated variation of seed oil and its component fatty acids; the major constituents of the oil were oleic, linoleic, and linolenic acid. Open-pollinated seed samples from individual plants were used for determining oil content and self-pollinated seed from the same plants for determining fatty acid composition. Oil content was calculated as per cent of the dry weight of the seed and fatty acids from the oil as per cent of total fatty acids and as per cent of the seed. Correlation coefficients were calculated for all pairs of fatty acids and for oil and each fatty acid.

When the quantities of fatty acids were expressed in relation to oil weight, as per cent of total fatty acids, there was a strong tendency for negative associations for oleic and other fatty acids and a tendency for linoleic and Iinolenic to be positively associated. These tendencies were attributed to a restriction on freedom for variation among 
the fatty acids which was imposed by expressing the fatty acids as per cent of total acids and in effect making the sum of the fatty acids equal to a constant (100\%).

When the quantities of fatty acids were expressed in relation to the seed weight, as per cent of the seed, there were no consistently significant correlation coefficients for any pair of fatty acids in the four populations of rape plants. Thus, the fatty acid components of the oil in these populations of rape generally tended to vary essentially independently of each other.

When both fatty acids and oil were expressed as per cent of the seed, there was a general tendency for positive associations for oil and fatty acids. This tendency was expected since oil is the sum of the fatty acids and a glycerol component. The positive association for oil and oleic was consistently high while those for oil and other fatty acids were relatively low or inconsistent. The high positive correlation for oil and oleic acid was attributed to both mathernatical and biological causes.

The evidence which has been presented indicates that a large component of mathematical origin occurs in correlation coefficients calculated from fatty acids expressed as per cent of total fatty acids or oil. This component is largely eliminated from correlation coefficients calculated from fatty acids expressed as per cent of seed. Therefore, correlation 
coefficients for fatty acids based on seed provide a much better estimate of actual relations in the plants than published correlation coefficients which are based on total fatty acids or oil. 


\section{LITERATURE CITED}

1. Canvin, D. T. 1965. Incorporation of acetate-1-C $\mathrm{C}^{14}$ into the longchain fatty acids of some oil seed crops. Can. J. Botany 43: 71-74.

2. Canvin, D. T. 1965. The effect of temperature on oil content and fatty acid composition of the oils from several oil seed crops. Can. J. Botany 43: 63-69.

3. Craig, B. M. 1961. Varietal and environmental effects on rapeseed. III. Fatty acid compositon of 1958 varietal tests. Can. J. Plant Sci. 41: 204-210.

4. Dominion Bureau of Statistics. 1964-65. Field Crop Reports. Queen's Printer, Ottawa.

5. Downey, R. K. 1963. Oil quality in rapeseed. Can. Food Ind. 34: $34-37$.

6. Downey, R. K., and B. i. Craig. 1964. Genetic control of fatty acid biosynthesis in rapeseed (Brassica napus L.).J.Am. Oil Chemists' Soc. 4l: 475-478.

7. Downey, R. K., and B. L. Harvey. 1963. Methods for breeding for' oil quality in rape. Can. J. Plant Sci. 43: 271-275.

8. Dybing, C. D., and D. C. Zimmerman. 1965. Temperature effects on flax (Linnum usitatissimum L.) growth, seed production, and oil quality in controlled environments. Crop Sci. 5: 184-185.

9. Harvey, B. L., and R. K. Downey, 1964. The inheritance of erucic acid content in rapeseed (Brassica napus $L_{0}$ ). Can. J. Plant Sci. 44: 104-111.

10. Hilditch, T. P., and P. N. Williams. 1964. The chemical constitution of natural fats. Chapman \& Hall, London.

11. Horowitz, B., and C. Winter. 1957. A new safflower oil with low iodine value. Nature 197: 582-583.

12. Howell, R. W., and F. I. Collins. 1957. Factors affecting linolenic and linoleic acid content of soybean oil. Agron. J. 49: 593-597.

13. James, A. T. 1962. The biosynthesis of unsaturated fatty acids in isolated plant leaves. Biochirn. Biophys. Acta $57: 167-169$. 
14. Johnson, I. J. 1932. Correlation studies with strains of flax with particular reference to the quantity and quality of the oil. Agron. J. 24: 537-544.

15. Johnson, H. W., and R. I. Bernard. 1962. Soybean genetics and breeding. Advances in Agronomy 14: 149-221.

16. Knowles, P. F., and A. B. Hill. 1964. Inheritance of fatty acid content in the seed oil of a safflower introduction from Iran. Crop Sci. 4: 406-409.

17. Knowles, P. F. , and A. Wutwakil. 1963. Inheritance of low iodine value of safflower selections from India. Econom. Bot. 17: 139-145.

18. Kondra, Z. P. 1964. The inheritance of erucic, eicosenoic and other fatty acid components of rapeseed oil. M. Sc. Thesis, University of Manitoba.

19. Lööf, B., and L. A. Appelqvist. 1964. Breeding work in rape, turnip rape and white mustard in connection with research on the composition of the fatty acids in their seeds. Zeitschrift fur Pflanzenzuchtung 52: 113-126.

20. Mcliahon, V., and P. K. Stumpf. 1964. Synthesis of linoleic acid by particulate system from safflower seeds. Biochim. Biophys. Acta 84: 359-361.

21. McNair, J. B. 1945. Plant fats in relation to environment and evolution. Bot. Rev. 1I: 1-59.

22. Olsson, G. 1960. Some relations between number of seeds per pod, seed size and oil content and the effects of selection for these characters in Brassica and Sinapsis. Hereditas 46: 29-70.

23. Painter, E. P., I. L. Nesbitt, and T. E. Stoa. 1944. The influence of seasonal conditions on oil formation and changes in iodine number during growth of flax. Agron.
$J_{.} 36: 204-213$.

24. Snedecor, G. W. 1956. Statistical methods. 5th ed. Iowa State College Press, Ames, Iowa.

25. Siemens, B. A。 1962. Effect of temperature on several characteristics of summer rape (Brassica napus $I_{\bullet}$ ). M. Sc. Thesis, University of Manitoba. 
26. Simmons, R. O., and F.W. Quackenbush. 1954. Comparative rates of formation of fatty acids in the soybean seed during its development. J. Am. Oil Chemists' Soc. 3I: $601-603$.

27. Simmons, R. $O_{\text {. }}$, and F. W. Quackenbush. 1954. The sequence of formation of fatty acids in developing soybean seeds. J.Am. Oil Chemists' Soc. 31: 44I-443.

28. Sims, R. P. A. 1964. Changes in fatty acid composition of the seeds of three oil-bearing species during increasing seed maturity. Can. J. PIant Sci. 44: 217-218.

29. Sims, R. P. A., W. G. McGregor, A. C. Plessers, and J. C. Mes. 1961. Lipid changes in maturing oil-bearing plants. I. Gross changes in safflower and flax. J. Am. Oil Chemists' Soc. 38: 273-276.

30. Sosulski, F. W. and R. F. Gore. 1964. The effect of photoperiod and temperature on the characteristics of flaxseed oil. Can. J. Plant Sci. 44: 381-382.

31. Stefansson, B. R., and F. W. Hougen. 1964. Selection of rape plants (Brassica napus $L_{0}$ ) with seed oil practically free from erucic acid. Can. J. Plant Sci. 44:
359-364.

32. Stefansson, B. R., F. W. Hougen, and B. K. Downey. 1961. Note on the isolation of rape plants. with seed oil free from erucic acid. Can. J. Plant Sci. 4I: 218-219.

33. Troeng, S. 1955. Oil determination of oilseed. Gravimetric routine method. J.Am. Oil Chemists' Soc. 32:
$124-126$.

34. White, H. B., F. W. Quackenbush, and A. H. Probst. 1961. Occurrence and inheritance of Iinolenic and Iinoleic 38: II3-117. 